\title{
Stage III Mucosal Melanoma of the Head and Neck AJCC v7
}

National Cancer Institute

\section{Source}

National Cancer Institute. Stage III Mucosal Melanoma of the Head and Neck A/CC v7. NCI Thesaurus. Code C87532.

Stage III includes: T3, NO, M0. T3: Mucosal disease N0: No regional lymph node metastases. M0: No distant metastasis. (AJCC 7th ed.) 